\title{
The Benefits of Fish Meal in Aquaculture Diets ${ }^{1}$
}

\section{R.D. Miles and F.A. Chapman ${ }^{2}$ \\ Introduction}

Fishmeal is recognized by nutritionists as a high-quality, very digestible feed ingredient that is favored for addition to the diet of most farm animals, especially fish and shrimp. Fishmeal carries large quantities of energy per unit weight and is an excellent source of protein, lipids (oils), minerals, and vitamins; there is very little carbohydrate in fishmeal.

\section{What Is Fishmeal}

Fishmeal is a generic term for a nutrient-rich feed ingredient used primarily in diets for domestic animals, sometimes used as a high-quality organic fertilizer. Fishmeal can be made from almost any type of seafood but is generally manufactured from wild-caught, small marine fish that contain a high percentage of bones and oil, and usually deemed not suitable for direct human consumption. These fishes are considered 'industrial' since most of them are caught for the sole purpose of fishmeal and fish oil production. A small percentage of fishmeal is rendered from the by-catch of other fisheries, and by-products or trimmings created during processing (e.g., fish filleting and cannery operations) of various seafood products destined for direct human consumption.

The fishmeal and fish oil industries are one of the few major animal industries existing today that still relies greatly on a "hunting-and-gathering" technique. Most fish rendered into meal and oil are captured at sea. Millions of tons of fishmeal are produced worldwide. Contrary to recent popular beliefs, most fishmeal and oil are produced from sustainable, managed, and monitored fish stocks, reducing the possibility of over-fishing. The supply is presently stable at 6.0 to 6.5 million tons annually. Approximately 4 to 5 tons of whole fish are required to produce 1 ton of dry fishmeal. Peru produces almost one-third of the total world fishmeal supply. Other principal fishmeal-producing countries are Chile, China, Thailand, U.S.A., Iceland, Norway, Denmark, and Japan (Table 1). Major groups of industrial fish rendered into fishmeal are anchovies, herrings, menhaden, sardines, shads, and smelts (Table 2).

Fish can be processed at sea in factory ships or caught and stored until they are transported to a processing facility on the coast. Fish is a highly perishable raw material, and spoilage will occur if it

1. This document is FA122, one of a series of the Department of Fisheries and Aquatic Sciences, Florida Cooperative Extension Service, Institute of Food and Agricultural Sciences, University of Florida. First published: May 2006. Please visit the EDIS Web Site at http://edis.ifas.ufl.edu.

2. R.D. Miles, Professor, Department of Animal Sciences, and F.A. Chapman, Associate Professor, Department of Fisheries and Aquatic Sciences; Florida Cooperative Extension Service, Institute of Food and Agricultural Sciences, University of Florida, Gainesville, FL 32611. 
is not processed in a timely manner. Preservation using ice or refrigerated seawater is common.

Table 1. Top fishmeal producing countries.

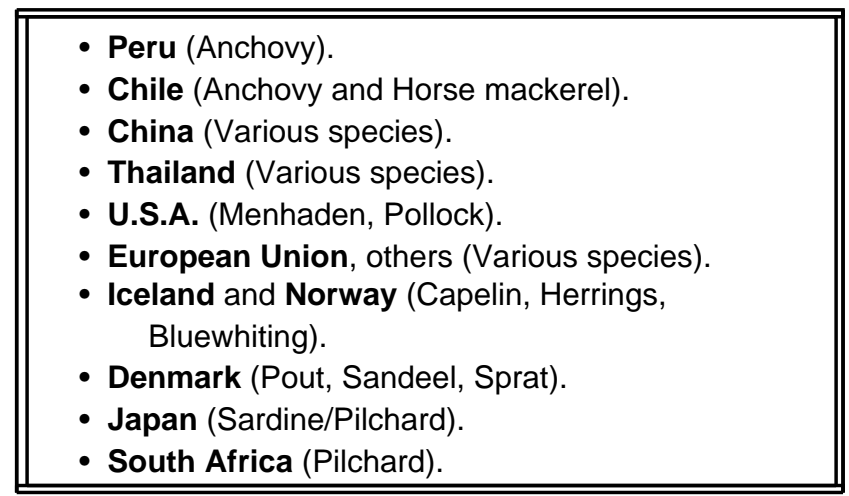

Cooking, pressing, drying and grinding the fish make fishmeal. There are several processing methods to produce good quality fishmeal, but the basic principle involves separation of the solids from the oil and water. When no oil needs to be removed, such as with lean fish, the pressing stage is often omitted. During cooking, the fish move through a long, steam-jacketed, screw conveyor cylinder, that coagulates the tissue proteins. This is a critical process, also responsible for sterilizing the product and preparing it for removal of the "liquor", which is a mixture of oil, water, and soluble protein. Once cooked, the liquor is removed by pressing, and the solid residue that remains is called "presscake". The liquor is centrifuged to remove the oil, which is often further refined before being transported to storage tanks. Prior to storage, it is essential to add an antioxidant to stabilize the oil, and the stored oil should not come into contact with air, heat or light to maintain its quality.
Table 2. Principal fish species in fishmeal. Most of these fishes are small, bony, with high content of oil, and considered of little edible use (e.g., anchovies, herrings, capelin, menhaden). A small percentage of fishmeal is rendered from fish offal, trimmings or cuttings, and other wastes principally from filleting and canning operations from the edible fisheries (e.g., tuna, cod, haddock, hake, pollock).

\begin{tabular}{||l||}
\hline \hline Anchovies (Engraulidae): \\
e.g., Peruvian anchoveta (Engraulis ringens); \\
Japanese anchovy (Engraulis japonicus). \\
\hline Herrings, Menhaden, Sardines and Shads \\
(Clupeidae): \\
e.g., Atlantic herring (Clupea harengus); \\
Menhaden (Brevoortia tyrannus and B. patronus); \\
South American and Japanese pilchards (Sardinops \\
sagax) and other species; European pilchard \\
(Sardina pilchardus); European sprat (Sprattus sprattus). \\
\hline Smelts (Osmeridae): \\
e.g., Capelin (Mallotus villosus). \\
\hline Jacks (Carangidae): \\
e.g., Chilean horse mackerel (Trachurus murphyi), \\
Atlantic horse mackerel (Trachurus trachurus). Pollock, \\
Cod, and Haddock (Gadidae) e.g., Walleye or Alaska \\
Pollock (Theragra chalcogramma); \\
Atlantic and Pacific cods (Gadus morhua and \\
G. cephalus); \\
Georges Bank haddock (Melanogramus aeglefinus); \\
Norway pout (Trisopterus esmarkil); \\
Blue whiting (Micromesistius poutassou). \\
\hline Hakes (Merlucciidae) and Sand lances \\
(Ammodytidae): \\
e.g., Hake (Merluccius sp.); \\
Hoki (Macruronus novaezelandie). \\
Small and lesser sandeels \\
(Ammodytes marinus and Ammodytes tobianus). \\
\hline Tunas and Mackerels (Scombridae): \\
e.g., Skipjack tuna (Katsuwonos pelamis), Yellowfin tuna \\
(Thunnus albacares); \\
Chub mackerel (Scomber japonicus), Atlantic mackerel \\
(S. scombrus). \\
\hline Cutlassfishes (Trichiuridae): \\
e.g., Largehead hairtail or Atlantic cutlassfish (Trichiurus \\
lepturus). \\
\hline \hline
\end{tabular}

After the oil and suspended solids are removed from the liquor, the remaining liquid is referred to as "stickwater" (about $65 \%$ of the raw material). Stickwater is a valuable product containing minerals, vitamins, some residual oil, and as much as $20 \%$ soluble and undissolved (suspended) proteins. The stickwater is evaporated to a consistency of thick syrup containing from $30 \%$ to $50 \%$ solids. This 
material can be sold as "condensed fish solubles", or it can be added back to the presscake and dried with it. Therefore, one can purchase "presscake" meal or a "whole" meal (where all of the solubles have been added back). The meals are then dried so that the moisture content is low enough to allow the meal to be stored and transported without any substantial mold or bacterial growth. Drying can be either direct or indirect; direct drying is the most rapid and requires very hot air to be passed over the meal as it is rapidly tumbled in a cylindrical drum. If the drying process is not carefully controlled or over-drying occurs, the fishmeal may be scorched and the nutritional value of the meal will be adversely affected. Indirect drying requires a steam-jacketed cylinder or a cylinder containing steam-heated discs that tumble the meal. Once the fishmeal is dried it is ground, screened to the correct particle size, and packed in bags or stored in silos for bulk delivery to companies throughout the world.

\section{Benefits of Fishmeal Incorporated into Fish Diets}

- Most commercial fishmeal is made from small, bony, and oily fish that otherwise are not suitable for human consumption and some is manufactured from by-products of seafood processing industries.

- Addition of fishmeal to animal diets increases feed efficiency and growth through better food palatability, and enhances nutrient uptake, digestion, and absorption.

- The balanced amino acid composition of fishmeal complements and provides synergistic effects with other animal and vegetable proteins in the diet to promote fast growth and reduce feeding costs.

- Fishmeal of high quality provides a balanced amount of all essential amino acids, phospholipids, and fatty acids (e.g.,DHA or docosahexaenoic acid and EPA or eicosapentaenoic acid) for optimum development, growth, and reproduction, especially of larvae and brood stock. The nutrients in fishmeal also aid in disease resistance by boosting and helping to maintain a healthy functional immune system.
- High-quality fishmeal also allows for formulation of nutrient-dense diets, which promote optimal growth.

- Incorporation of fishmeal into diets of aquatic animals helps to reduce pollution from the wastewater effluent by providing greater nutrient digestibility.

- The incorporation of high-quality fishmeal into feed imparts a 'natural or wholesome' characteristic to the final product, such as that provided by wild fish.

\section{Protein Quality of Fishmeal}

High-quality fishmeal normally contains between $60 \%$ and $72 \%$ crude protein by weight. From a nutritional standpoint, fishmeal is the preferred animal protein supplement in the diets of farm animals and often the major source of protein in diets for fish and shrimp. Typical diets for fish may contain from $32 \%$ to $45 \%$ total protein by weight, and diets for shrimp may contain $25 \%$ to $42 \%$ total protein. The percentages of inclusion rate of fishmeal in diets for carp and tilapia may be from $5-7 \%$, and up to $40 \%$ to $55 \%$ in trout, salmon, and some marine fishes. A typical inclusion rate of fishmeal in terrestrial livestock diets is usually $5 \%$ or less on a dry matter basis.

Any complete diet must contain some protein, but the nutritional value of the protein relates directly to its amino acid composition and digestibility. Proteins are made of amino acids, which are released for absorption into the blood following protein digestion. Animals have requirements for specific amino acids rather than protein. Fishmeal and any other feedstuff that contains protein can simply be thought of as a 'vehicle' for providing amino acids to the diet. Animals build proteins from combinations of about 22 amino acids. However, animals cannot make all 22 of these amino acids in their body. Amino acids that cannot be synthesized by the animal, and therefore must be supplied in the diet, are classified as "essential". Ten essential amino acids must be contained in the diet of fish: Arginine, Histidine, Isoleucine, Leucine, Lysine, Methionine, Phenylalanine, Threonine, Tryptophan, and Valine. Amino acids that can be synthesized by the animal 
are termed "nonessential" and do not have to be added to the diet. A protein that does not contain the proper amount of a required (essential) amino acid would be considered an imbalanced protein and would have a lower nutritional value. The amino acid present in the least amount relative to the animal's requirement for that particular amino acid is referred to as the "limiting" amino acid.

The amino acid profile of fishmeal is what makes this feed ingredient so attractive as a protein supplement (Table 3). Proteins in cereal grains and other plant concentrates do not contain complete amino acid profiles and usually are deficient in the essential amino acids lysine and methionine. Soybean and other legume meals, which are widely used in the diets of most farm animals such as pigs and chickens, are a good source of lysine and tryptophan but are limiting in the sulfur-containing amino acids methionine and cystine. An animal's requirement for a limiting amino acid can be met by simply adding more of the protein. However, this would be very costly, and the excess nitrogen in the protein would deleteriously affect water quality. Excess nitrogen arising from the amino acids of proteins is excreted from the fish into the water in the form of ammonia. Ammonia is toxic to fish and must be removed from the water by filtration or water flushing.

The quality of different feedstuffs is greatly dependant on the amino acid profile in their proteins, digestibility of the proteins, freshness of the raw materials, and their storage. Plant-based proteins, even when properly processed, are usually not as digestible as fishmeal; and their inclusion rate into the diet is often limited as it results in depressed growth rates and feed intake. Over-all protein digestibility values for fishmeal are consistently above $95 \%$. In comparison protein digestibility for many plant-based proteins varies greatly, for example, from $77 \%$ to $96 \%$, depending on the species of plant. The structural nature of plants is totally different from that of animals. Proteins isolated from plants are associated with indigestible non-structural carbohydrates (oligosaccharides) and structural fiber components (cellulose), which are not associated with animal proteins. It is the presence of these components which are thought to be contributing obstacles to efficient utilization of proteins in many economically plant-based feedstuffs. The lack of nutritional inhibitors or anti-nutritional factors in fishmeal also makes this meal more attractive than plant proteins for use in aquaculture diets.

Anti-nutritional factors are compounds that interfere with nutrient digestion, uptake, or metabolism and can also be toxic. For example, a naturally occurring anti-nutritional factor in uncooked soybeans is the Kunitz trypsin-inhibitor that prevents the enzyme trypsin from breaking down dietary proteins in the intestine of animals. Lathyrogens in chickpeas also disrupt collagen formation. Collagen is the most abundant protein present in animals, making up most connective tissue and providing structural support. Thiaminases found in raw fish are known to destroy thiamine (vitamin $\mathrm{B}_{1}$ ), and the avidin in egg white binds biotin (another water-soluble vitamin of the B-complex). Gossypol is another anti-nutritional factor found in cottonseed meal/oil that is toxic to animals and lowers fertility in males.

Another very important reason why fishmeal is sought after as an ingredient in aquaculture diets is because fishmeal contains certain compounds that make the feed more acceptable and agreeable to the taste (palatable). This property allows for the feed to be ingested rapidly, and will reduce nutrient leaching. It is thought the non-essential amino acid glutamic acid is one of the compounds that imparts to fishmeal its palatability.

\section{Lipid Content in Fishmeal}

The lipids in fishes can be separated into liquid fish oils and solid fats. Although most of the oil usually gets extracted during processing of the fishmeal, the remaining lipid typically represents between $6 \%$ and $10 \%$ by weight but can range from $4 \%$ to $20 \%$. Fish lipids are highly digestible by all species of animals and are excellent sources of the essential polyunsaturated fatty acids (PUFA) in both the omega- 3 and omega- 6 families of fatty acids. The predominant omega-3 fatty acids in fishmeal and fish oil are linolenic acid, docosahexaenoic acid (DHA), and eicosapentaenoic acid (EPA). Both DHA and EPA fatty acids are produced and passed along the food chain by small-size algae and zooplankton, which are consumed by fish. Fishmeal and oil contain more omega-3, than omega- 6 fatty acids. In contrast, 
Table 3. Percentage of essential amino acids (EAA) ${ }^{1}$ in fishmeal (FM), rendered meat meal (MM), poultry by-product meal (PBM), blood meal (BM), soybean meal (SBM). Percentage of crude protein in the meal (in parenthesis).

\begin{tabular}{|c|c|c|c|c|c|}
\hline Essential Amino Acid & $\begin{array}{c}\text { FM } \\
(64.5 \%)^{2}\end{array}$ & $\begin{array}{c}\text { MM } \\
(55.6 \%)^{2}\end{array}$ & $\begin{array}{c}\text { PBM } \\
(59.7 \%)^{2}\end{array}$ & $\begin{array}{c}\text { BM } \\
(89.2 \%)^{2}\end{array}$ & $\begin{array}{c}\text { SBM } \\
(50.0 \%)^{2}\end{array}$ \\
\hline Arginine & 3.82 & 3.60 & 4.06 & 3.75 & 3.67 \\
\hline Histidine & 1.45 & 0.89 & 1.09 & 5.14 & 1.22 \\
\hline Isoleucine & 2.66 & 1.64 & 2.30 & 0.97 & 2.14 \\
\hline Leucine & 4.48 & 2.85 & 4.11 & 10.82 & 3.63 \\
\hline Lysine & 4.72 & 2.93 & 3.06 & 7.45 & 3.08 \\
\hline Methionine + Cystine $^{3}$ & 2.31 & 1.25 & 1.94 & 2.32 & 1.43 \\
\hline Phenylalanine + Tryosine ${ }^{4}$ & 4.35 & 2.99 & 3.97 & 8.47 & 4.20 \\
\hline Threonine & 2.31 & 1.64 & 0.94 & 3.76 & 1.89 \\
\hline Tryptophan & 0.57 & 0.34 & 0.46 & 1.04 & 0.69 \\
\hline Valine & 2.77 & 2.52 & 2.86 & 7.48 & 2.55 \\
\hline \multicolumn{6}{|c|}{$\begin{array}{l}{ }^{1} \text { The percentage values for the EAA composition of each feedstuff were taken from the } 1993 \text { NRC (National } \\
\text { Research Council, Nutrient Requirements of Fish, National Academy of Sciences, Washington, DC). } \\
{ }^{2} \text { Percentage of total crude protein in feedstuff. } \\
{ }^{3} \text { Cystine can be synthesized from methionine. } \\
{ }^{4} \text { Tyrosine can be synthesized from phenylalanine. }\end{array}$} \\
\hline
\end{tabular}

most plant lipids contain higher concentrations of omega- 6 fatty acids. For example, oil extracted from soybeans, corn, or cottonseed is rich in linoleic acid, an omega-6 fatty acid. Some oils, like those from canola and flax seeds contain linolenic acid (of the omega-3 family), however, its conversion into essential DHA and EPA by most animals may be limited.

The beneficial effects of lipids in fish diets are particularly evident in structure and function of cell membranes. The cell membrane is a semi-permeable and flexible layer that encloses each cell in animals and controls the passage of nutrients and other substances in and out of the cell interior. The cell membrane protects the cell and is composed primarily of lipids, proteins, and some carbohydrates. Because of their fatty acid composition, lipids permit cell membranes to maintain their fluidity in decreasing or increasing water temperatures and cushion cells from the dramatic pressure changes that fish encounter at varying depths in the water column. Essential fatty acids are necessary for normal larval development, fish growth, and reproduction. They are important in normal development of the skin, nervous system, brain, and visual acuity. PUFAs appear to assist the immune system in defense of disease agents and reduce the stress response. Fishmeal also contains valuable phospholipids, fat-soluble vitamins, and steroid hormones.

\section{Energy in Fishmeal}

The lipids in fishmeal not only impart an excellent profile of essential fatty acids but also provide a high content of energy to the diet. Since there is very little carbohydrate in fishmeal, the energy content of fishmeal relates directly to the percentage of protein and oil it contains. The quantity and quality of oil in fishmeal will in turn depend on the species, physiology, sex, reproductive status, age, feeding habits of the captured fish, and the method of processing.

The lipids in fishmeal and fish oil are easily digested by all animals, especially fish, shrimp, poultry, pigs, and ruminants such as cows, sheep, and goats. In these animals the lipid digestibility is $90 \%$ or greater. The high digestibility of fish lipids means they can provide lots of usable energy. If a diet does not provide enough energy, the fish or shrimp will have to break down valuable protein for energy, 
which is expensive and can increase production of toxic ammonia.

Good quality fishmeal contains antioxidants or compounds that reduce the possibility of damage from highly reactive toxic substances which are continually produced at the molecular level in animal cells. For example, lipids especially PUFAs, are easily damaged and become rancid when exposed to oxygen, a process known as oxidation and one that releases heat. The use of antioxidants in the preservation of fishmeal is essential in order to stabilize its energy value because there are high quantities of PUFAs present in the oil. Without stabilizing fishmeal with antioxidants the available energy content of the meal may be reduced by as much as $20 \%$; the oxygen will modify (damage) the chemical structure of the PUFAs and therefore less energy is available to the animal. Prior to the development and use of antioxidants by the fishmeal industry, it was common practice to turn piles of processed meal in order to dissipate the heat arising from oxidation. Occasionally, fishmeal would ignite spontaneously and cause fires while being shipped or stored. Historically, it was known that ships sank at sea due to fires caused by spontaneous combustion of the fishmeal they were transporting. Today, antioxidants added to fishmeal prevent such catastrophes.

\section{Mineral and Vitamin Value of Fishmeal}

When a sample of feed is taken to the laboratory and analyzed for nutrient content, the procedure involves burning a portion of the sample. Ash is the material remaining after the feed sample is completely burned. Normally, the ash content of good quality fishmeal averages between $17 \%$ and $25 \%$. More ash indicates a higher mineral content, especially calcium, phosphorus, and magnesium. Calcium and phosphorus constitute the majority of the ash found in fishmeal. Unlike the phosphorus in plants, phosphorus in fishmeal is in a form highly available to most animals. The phosphorus in plants is not as readily available to monogastric animals (having a one-compartment stomach like pigs, dogs, and humans) because it is primarily in the organic form known as phytate. Ruminants such as cows, sheep, and goats are able to utilize phosphorus in phytate due to the microbial population in their rumen, which is one of the four compartments in the stomach of ruminants.

The vitamin content of fishmeal is highly variable and influenced by several factors, such as origin and composition of the fish, meal processing method, and product freshness. The content of fat-soluble vitamins in fishmeal is relatively low because of their removal during extraction of the oil. Fishmeal is considered to be a moderately rich source of vitamins of the B-complex especially cobalamine $\left(\mathrm{B}_{12}\right)$, niacin, choline, pantothenic acid, and riboflavin.

\section{Economic and Environmental Considerations of Fishmeal Utilization}

The high quality and concentration of essential nutrients, especially of well-balanced amino acids, essential fatty acids, and energy content makes fishmeal an indispensable ingredient in diets of most aquaculture species and many land-farm animals. Because of its nutrient content, high digestibility and palatability, fishmeal serves as the benchmark ingredient in aquaculture diets.

Table 4. Use of fishmeal by agriculture.

\begin{tabular}{||l|c|c||}
\hline \hline Sector & \multicolumn{2}{|c|}{$\mathbf{2 0 0 2}$ Year $\mathbf{2 0 1 0}$} \\
\hline Aquaculture & $46 \%$ & $56 \%$ \\
\hline Pigs & $24 \%$ & $20 \%$ \\
\hline Poultry & $22 \%$ & $12 \%$ \\
\hline Ruminants & $1 \%$ & $<1 \%$ \\
\hline Other & $7 \%$ & $12 \%$ \\
\hline \hline
\end{tabular}

The majority of fishmeal produced is incorporated into commercial diets fed to fish, shrimp, swine, poultry, dairy cattle, and other animals such as mink (Table 4). It is unlikely that supplies of commercially available fishmeal and oil will be able to keep pace with the projected increase in worldwide production of aquaculture and terrestrial animal feeds. In most recent years, aquaculture has used approximately $46 \%$ of the total annual fishmeal production, a figure that is expected to rise as demand for aquaculture products increases in the next decade. 
Optimal use of fishmeal in practical aquaculture diets is necessary to minimize feeding costs which can account for $40 \%$ or more of operating expenses. The concentration of high-quality nutrients, especially protein, makes fishmeal one of the most sought and expensive feedstuffs. The cost of high-quality fishmeal (65\% protein) has ranged from approximately $\$ 385$ to $\$ 554$ per ton since the year 2000 , or 2.0 to 3.5 times the price of soybean meal.

Unfortunately, the specific dietary requirements for energy, essential amino acids, fatty acids, and other nutrients are not yet known for many aquaculture species. Also, the digestibility of different feedstuffs has not yet been established for many of the commercially important fish species. Therefore, there has been a reluctance to diminish the total amount of fishmeal used in many of the different aquaculture diets. Simply, over-supplementing the diet with high-quality fishmeal is an easy and very successful way of overcoming lack of knowledge about aquaculture diets in relation to specific nutrient requirements and digestibility of feedstuffs.

The best approach in feed formulation is to use high-quality feedstuffs to manufacture a diet that meets the nutritional and energy requirements of the aquaculture species in question. Fishmeal contains the profile of amino acids that most closely meets the amino acid requirements of fish. If a portion or all of the fishmeal in a diet can be replaced successfully with other high-quality protein sources, doing so will contribute greatly towards protecting the surrounding environment and promoting a sustainable aquaculture industry. New information on nutrient requirements of aquatic organisms coupled with advances in feed technology indicates that species-specific fish diets can be made by partial or total replacement of fishmeal with other plant and animal proteins. All-plant protein-based diets containing soybean meal, cottonseed meal, and middlings from corn and wheat, supplemented with lysine and methionine, have been used successfully to grow juvenile catfish, carp, and tilapia to market size. However, larvae and young fish still require fishmeal to grow at an optimal rate. Animal proteins and fats, by-products of the animal-rendering industry, can be used in aquaculture diets because they also provide essential amino acids and fatty acids. These "fishmeal substitutes" will be used more extensively by the aquaculture industry in the future.

Fishmeal belongs to a short list of excellent feedstuffs that provide essential nutrients in a highly digestible concentrated form. The use of fishmeal in domestic and farm animal diets will remain a core and efficient practice, particularly for young, rapidly growing, and high-producing animals like maturing fish, berried (egg-laden) shrimp, poultry, and lactating dairy cattle. The beneficial effects of eating wholesome foods will increase the worldwide demand for seafood products resulting in increased use of fishmeal. Fish fed diets formulated with a high percentage of fishmeal will contain high concentrations of the PUFAs in their tissues. These fish and their fillets are very beneficial to people due to the well-known attributes of the PUFAs, especially of the omega-3 family. PUFAs are essential for human biological functions, particularly the production of prostaglandins. PUFAs and prostaglandins may ameliorate many human health disorders, such as high blood pressure, heart disease, arthritis, migraines, diabetes, and cancer.

Incorporation of DHA and EPA found in fishmeal into the diets of fish and other farm animals is an efficient method to ensure a proper concentration of these important omega-3 fatty acids in the human diet.

Balancing nutrients in diets by using the minimum amount of fishmeal to meet specific amino acid requirements for fast growth and reproduction and reducing feed costs constitute one of the principal objectives in formulation of fish feeds. Another important aim in feed formulation is to increase dietary nutrient density and digestibility of the feed to increase biological performance and to reduce nutrient leaching and water-quality degradation. The aquaculture industry must continue to seek out alternative sources of high-quality plant and animal-based protein ingredients for their feedstuffs. Presently, this is an active area of research in aquaculture nutrition.

Further information on fishmeal can be found in the World Wide Web, in particular the "Fishmeal Information Network", URL Web site: http://www.fin.org.uk/ 